\title{
Principles to guide sustainable implementation of extended-scope-of-practice physiotherapy workforce redesign initiatives in Australia: stakeholder perspectives, barriers, supports, and incentives
}

This article was published in the following Dove Press journal:

Journal of Multidisciplinary Healthcare

20 June 2014

Number of times this article has been viewed

\author{
Joanne Morris' \\ Karen Grimmer ${ }^{2}$ \\ Lisa Gilmore' \\ Chandima Perera ${ }^{3}$ \\ Gordon Waddington ${ }^{4}$ \\ Greg Kyle ${ }^{4}$ \\ Bryan Ashman ${ }^{5}$ \\ Karen Murphy ${ }^{6}$ \\ 'The Physiotherapy Department, \\ The Canberra Hospital, ACT \\ Health, Canberra, ACT, Australia; \\ ${ }^{2}$ International Centre for Allied \\ Health Evidence, University of South \\ Australia, Adelaide, SA, Australia; \\ ${ }^{3}$ Department of Rheumatology, The \\ Canberra Hospital, Canberra, ACT, \\ Australia; ${ }^{4}$ The Faculty of Health, \\ University of Canberra, Canberra, \\ ACT, Australia; ${ }^{5}$ Department of \\ Surgical Services, The Canberra \\ Hospital, Canberra, ACT, Australia; \\ ${ }^{6}$ Office of Allied Health Advisor, ACT \\ Health, Canberra, ACT, Australia
}

\begin{abstract}
Sustainable implementation of new workforce redesign initiatives requires strategies that minimize barriers and optimize supports. Such strategies could be provided by a set of guiding principles. A broad understanding of the concerns of all the key stakeholder groups is required before effective strategies and initiatives are developed. Many new workforce redesign initiatives are not underpinned by prior planning, and this threatens their uptake and sustainability. This study reports on a cross-sectional qualitative study that sought the perspectives of representatives of key stakeholders in a new workforce redesign initiative (extended-scopeof-practice physiotherapy) in one Australian tertiary hospital. The key stakeholder groups were those that had been involved in some way in the development, management, training, funding, and/or delivery of the initiative. Data were collected using semistructured questions, answered individually by interview or in writing. Responses were themed collaboratively, using descriptive analysis. Key identified themes comprised: the importance of service marketing; proactively addressing barriers; using readily understood nomenclature; demonstrating service quality and safety, monitoring adverse events, measuring health and cost outcomes; legislative issues; registration; promoting viable career pathways; developing, accrediting, and delivering a curriculum supporting physiotherapists to work outside of the usual scope; and progression from "a good idea" to established service. Health care facilities planning to implement new workforce initiatives that extend scope of usual practice should consider these issues before instigating workforce/model of care changes.
\end{abstract}

Keywords: extended scope physiotherapy, role redesign, business case development, models of care, workforce reform enablers

\section{Introduction}

Extended-scope-of-practice (ESP) in physiotherapy has been in place in the UK for over 20 years. ${ }^{1}$ ESP physiotherapists undertake tasks that exceed their formally accepted competencies. ${ }^{2}$ One driver for introducing these new roles in the UK was to provide an alternative workforce that could take up activities relinquished by junior medical staff in the National Health Service (NHS) ${ }^{3,4}$ when enterprise bargaining restricted doctor work hours. ${ }^{5,6}$ Thus, UK ESP physiotherapy roles were generally implemented to provide alternative pathways of care for orthopedic patients, to relieve workload pressures on medical staff, and improve patient waiting times. ${ }^{7-9}$ The new physiotherapy
Correspondence: Joanne Morris Physiotherapy Department, Canberra Hospital, Level I, Building 3, Yamba Dr, Garran, ACT, 2605, Australia Email jo.morris@act.gov.au 
roles provided one approach that facilitated hospital achievement of service access targets. ${ }^{10,11}$ Much of the research into the impact of ESP physiotherapy in the UK has reported on outcome measures of safety, cost, and access. ${ }^{8,11}$ However, because of the need to act quickly to ensure service continuity in the UK, the new physiotherapy roles were introduced without nationally planned training or credentialing. ${ }^{1,12,13}$ As a result, physiotherapists were trained and credentialed "inhouse" in reading imaging, prescribing, and administering medicines (including injecting). ${ }^{1,12,13}$ Whilst meeting local and national access requirements, the reliance on in-house ESP training meant that few ESP physiotherapists could work in this same role across hospitals as their skills were not transferrable.

ESP physiotherapy is a relatively new workforce initiative in Australia, adapted from UK experiences to address local/ institutional needs, such as doctor shortages, long waiting lists, and/or long waiting times. ${ }^{14-18}$ Like any new business initiative, introducing ESP physiotherapy services requires a credible driver (ie, why do it?) and sound planning to ensure accountability, acceptability, and sustainability of the role. ${ }^{19,20}$ Thus, a comprehensive business case is required to consider the new initiative from all angles, before a decision can be made to implement it. The business case for ESP physiotherapy services should demonstrate that the new service can be provided, is of sound and demonstrable quality, fills a recognized gap, is self-supporting, and benefits patient care by providing better access to the right health care (usually without inflating costs). ${ }^{20}$ Without guidance regarding the range of issues that need to be considered in such a business case, vital business issues may be overlooked and new workforce initiatives may fail, despite best intentions and evidence that it could fill local need.

There are increasing pressures on the current Australian health workforce to deliver effective services to escalating numbers of patients, many with chronic and complex diseases. ${ }^{18,21}$ Extended-scope allied health services are one workforce redesign initiative that could viably assist in addressing this situation. However, because of the urgency to address these pressures, new ESP allied health initiatives in Australia run the risk of being developed in haste, conceptualized "on the run," and/or in reaction to pressing local need, rather than being preplanned with sustainability, accountability, profession-wide credibility, and acceptability in mind. ${ }^{22}$ There is thus a pressing need to develop a comprehensive list of elements that should be considered in a business case for extending scope of practice of allied health in Australia, to ensure that new, potentially effective workforce reform initiatives do not fail because of poor planning.

This paper presents stakeholder-informed guiding principles that could be considered in a business case for a new workforce initiative in extending scope of practice. These elements were derived from the perspectives of representatives of key stakeholder groups, in an ESP physiotherapy initiative introduced into one large Australian health care facility, regarding the important elements that need to be considered when planning a sustainable new service. In doing so, this qualitative study addressed important questions, relating to strategic management issues in health care, that arise with the introduction of a new and novel workforce redesign solution for service delivery concerns.

\section{Materials and methods Ethics approval}

Ethics approval was obtained from the Human Research Ethics Committee (ETHLR.13.208) at the ACT Health facility. The findings reported in this paper were derived as part of a broader evaluation strategy.

\section{Key stakeholders}

Eight stakeholder groups were involved in some way in the development, management, training, evaluation, funding, and/or delivery of the new ESP physiotherapy service. Representatives of each stakeholder group were identified by the research team as having knowledge of and/or insights into the workforce redesign initiative. The stakeholder groups and the representatives invited to participate in the research included:

- The state/territory Government

o Allied Health Adviser in the Health Department

o Chief Pharmacist

- The administering health care facility

o Director of Surgical Services

o Consultant rheumatologist

o Manager of Physiotherapy

o Inaugural ESP physiotherapist

- The local tertiary training institution

o Professor of Physiotherapy representing the local physiotherapy training program

o Associate Professor of Pharmacy - module coordinator and lecturer in the pharmacology course developed for the ESP physiotherapy initiative.

\section{Questions}

A core set of questions was asked of each participant: 
- What are your perspectives on the ESP physiotherapy service?

- What were/are the main barriers you experienced in your role in this initiative, and the ways to overcome them?

- What issues occurred that you did not anticipate? Individual and specific role/task questions were then asked, which reflected the nature of the engagement of each stakeholder group in the new service. These questions are available on request to the principal author.

\section{Data collection}

Individual invitation letters were sent to the representative stakeholders, listing the questions for the study and the names and positions of all others invited to participate in the research, so that each participant was comfortable with the context, engagement, and reach of the research. The participants were asked to confirm that they were appropriate representatives of the stakeholder group within which they had been nominated. A choice of ways of responding to questions was offered, including interview (telephone or face-to-face), email, or formal written responses. Where telephone or face-to-face interviews were preferred, the interview was audiotaped and independently transcribed for later analysis.

\section{Data synthesis}

Key themes from each response were identified collaboratively by two authors ( $\mathrm{JM}$ and $\mathrm{KG}$ ), and responses that described these themes were distilled, as described by Rice and Ezzy, ${ }^{23}$ and Fossey et al. ${ }^{24}$ Commonality of themes was mapped across stakeholder groups, and contextual differences in common themes were explored. Changes in the new service over time and how initial concerns had been addressed were considered, as well as the new concerns that had arisen as the ESP physiotherapy position had been rolled out. The current situation and challenges for the future were identified.

The findings were synthesized into broad principles that could be included in business plans developed by other institutions, prior to implementation of new workforce initiatives involving ESP roles, as a means of improving national consistency in the roll out of ESP roles, reducing repetition, and saving costs.

\section{Results and discussion}

This is the first known research that sought to identify important issues "from the field," related to the implementation of a new (and challenging) workforce redesign initiative involving extended scope of practice in allied health. Responses to the interview questions raised a range of strategic management issues that need to be considered prior to introducing a novel, sustainable workforce initiative to address a patient workflow problem. This paper provides assistance to health policy makers, managers, funders, and clinicians in Australia, and elsewhere, so that planning a workforce reform initiative that involves health care providers working out of scope does not overlook important issues that could significantly reduce sustainability and/or acceptability of the initiative.

All those who were invited to participate did so, and all agreed that they were appropriate representatives of the important stakeholder groups. Five participants provided written responses (two as emails), and three participated in audiotaped telephone calls.

Participants provided rich data that highlighted a range of issues that should be considered in a business case for workplace reform initiatives that extend the scope of usual allied health practice. Some of these issues had not been considered when this workforce redesign initiative had been conceptualized and developed, and had they been considered, some of the problems that emerged along the way may have been avoided. In order of mention, the issues raised related to broad themes of: clearly defining the (new) ESP; recruiting the right person to the position; supporting that person as the roles and responsibilities in the position evolved; formal training; managing the concerns of the physiotherapy staff; managing concerns of clinicians from other disciplines; financial management; legislative changes; quality practices; and common terminology. These are outlined in Table 1, along with explanatory and underpinning issues.

Table 2 reports the importance to participants of issues within the key themes, highlighting both the range of issues and the importance placed on these issues by participants from the different stakeholder groups. Figure 1 summarizes the broad themes in terms of the number of individual issues within each theme and the number of participants who mentioned each issue.

The requirement for formal training was noted by all participants, and thus, it could be assumed that it was relevant to all the stakeholder groups. Within this broad theme were noted the transparency and reproducibility of training provided to ESP-in-training physiotherapists, the nature of formal training, participation of other disciplines in the credentialing process of the physiotherapists working out of scope, and ways to demonstrate having been formally trained to assume roles traditionally undertaken by others. The importance placed on formal training in this Australian health 
Table I Broad themes and underpinning issues

\begin{tabular}{|c|c|}
\hline \multirow[t]{5}{*}{ Defining ESP } & Reaching mutual understanding of ESP tasks with other disciplines \\
\hline & Letting go of traditional discipline tasks \\
\hline & Identifying, promoting, and championing areas of health care within which to extend the \\
\hline & scope of practice \\
\hline & What does it mean to undertake tasks traditionally done by others? \\
\hline \multirow[t]{4}{*}{ Recruitment } & How to attract and recruit the "right" people \\
\hline & "Selling" the idea of shift work as part of the recruitment package \\
\hline & Ensuring that the applicants' requirements for part-time work fit in around private practice \\
\hline & and/or research commitments \\
\hline \multirow[t]{4}{*}{ Supporting the person in the position } & Adequate remuneration for the position \\
\hline & Human Resources recognition for the new position \\
\hline & Funding for continuing the position \\
\hline & Support to participate in formal training \\
\hline \multirow[t]{7}{*}{ Formal training } & The need for it \\
\hline & What constitutes formal training? \\
\hline & What constitutes appropriate and transferrable credentialing? \\
\hline & At what point is the ESP Physiotherapist-in-Training trained? \\
\hline & Building a business case for sustainable and ongoing training programs \\
\hline & Ensuring the longevity of training programs, given the need for regular updates of teaching \\
\hline & material balanced against small numbers of students \\
\hline \multirow[t]{2}{*}{ Managing the concerns of physiotherapy staff } & Increased in-house workload (data collection) \\
\hline & Resistance from the "in scope" staff \\
\hline \multirow[t]{2}{*}{ Managing other discipline concerns } & Having time to support/credential the ESP Physiotherapist-in-Training in the position \\
\hline & Resistance from other disciplines in the same area in relinquishing their traditional tasks \\
\hline \multirow[t]{3}{*}{ Financial management } & Backfill issues for ESP Physiotherapist-in-Training training \\
\hline & Receiving adequate remuneration to the Physiotherapy Department from other departments \\
\hline & using the ESP physiotherapist service \\
\hline \multirow[t]{3}{*}{ Legislative changes } & Defining and effecting the legislation changes required to support formal extended scope of \\
\hline & practice activities \\
\hline & Whose task is it to advance legislative changes? \\
\hline \multirow[t]{2}{*}{ Quality practice } & What is quality practice? \\
\hline & Assurance of safe practice acceptable to all \\
\hline Common terminology & Common understanding of wording and intent for pilot/project/initiative/service \\
\hline
\end{tabular}

Abbreviation: ESP, extended scope of practice.

service perhaps reflected a learning from the UK experience, where physiotherapists working out of scope have often been credentialed informally in their own institution to undertake site-specific extended scope tasks (based on support from, and sign off by, in-house medical specialists) and yet their training and competence may not be recognized elsewhere. ${ }^{1,4}$ The importance placed by our participants on training was linked with the need for external recognition of the capacity of physiotherapists to:

- competently undertake out-of-scope tasks and

- provide quality care that is recognized as such using different measures applied by different stakeholders (for instance the Institute of Medicine approach). ${ }^{25}$

Participants also noted the urgent need to underpin legislative changes with sound evidence of training and competence. ${ }^{3}$ To support formal training in musculoskeletal practice specific to ESP for physiotherapists in the workforce redesign initiative in Canberra Hospital, a formal training program was developed. This has been delivered to one cohort of physiotherapists at the local university and was independently evaluated. The evaluation report is currently being finalized; however, early findings indicate that participants concur that formal, recognized training for out-of-scope activities is essential to ensure clinical competence and to facilitate acceptance of the new skills of the ESP clinicians in the workplace. The training program was tailor-made for ESP allied health requirements (specifically physiotherapy), following lengthy and persistent engagement with tertiary providers. It was developed on a pilot business case model that "tested the waters" in terms of curriculum content that met the requirements of the discipline as well as the health care facility. The pilot program also tested the mode of delivery, evaluation using best practice teaching and learning frameworks, as well as implementation in the facility via credentialing and supervision by medical specialists. This program, and the emergence of others developed along similar lines in other Australian institutions, largely addressed the stakeholder 


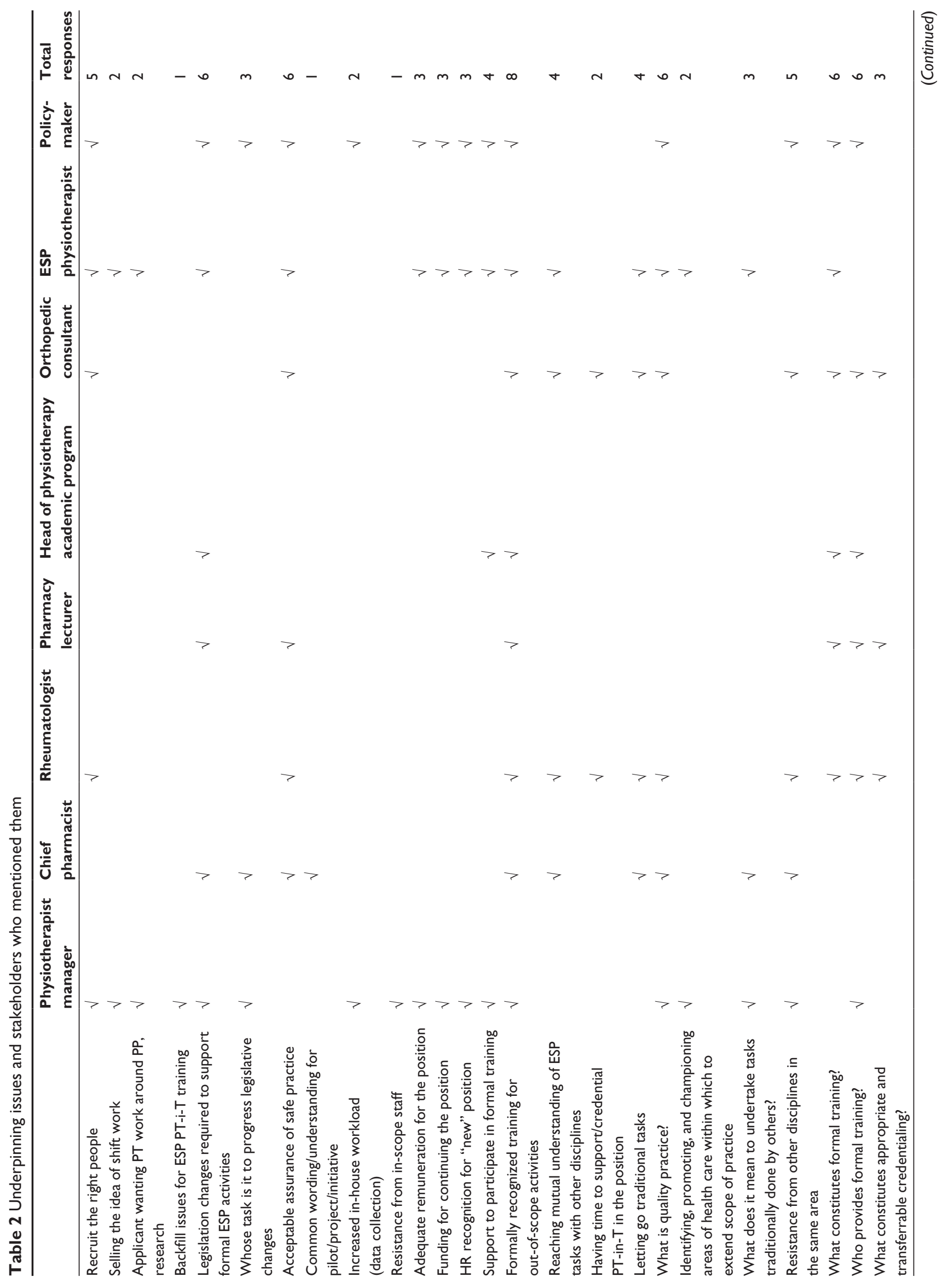




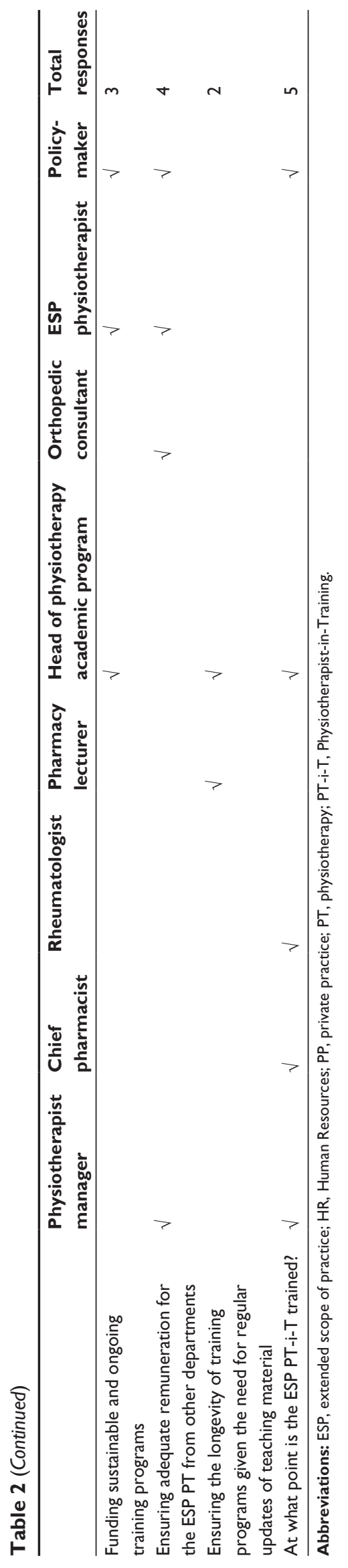

concerns raised in this paper, regarding sustainable, formal, high-quality training.

However, concerns about legislative change have not been similarly well-addressed, and this remains an issue for sustainability of an ESP physiotherapy service introduced anywhere in Australia. In Australia, national legislation underpins physiotherapists' registration to practice "within scope. ${ }^{226}$ However, there is individual state/territory legislation dealing with use of medicines; therefore, ESP physiotherapy roles that include the unsupervised prescription and supply of medicines require either amendment to national legislation or endorsement of prescribing activities for appropriately-trained individuals within specific state/territory legislation. ${ }^{27}$ Thus, a key future consideration is how best to address legislative change, for instance, the addition of a "prescribing caveat" to individual physiotherapists' national registration that identifies that they have undertaken an appropriate postgraduate pharmacology training program and a subsequent period of supervised practice.

Uncertainty about "when formal training is completed" was highlighted. This also relates to the broader issue of workforce reform nomenclature, specifically "when can the pilot phase be stopped and the new service accepted as part of the workforce?" When individual registration caveats to endorse practice are required for ESP activities, it appears from the concerns identified in this research that a "line in the sand" is required (which has not yet been defined) to indicate that a physiotherapist has achieved the training and formal recognition (within and outside the profession) required to allow them to practice out of usual scope, such that a "new" workforce initiative can become a recognized service. Acceptance of not only a new model of care but also, of a role redesign initiative is based on multiple components, not just outcomes from the initiative. It requires that key individuals in a range of positions recognize the allied health clinicians as agents of change in workforce reform and acknowledge the value and effectiveness of the ESP initiative (and not self-interest or promotion of the profession) as the key driver. Thus, the adoption of an overt and recognized change-management process, to support a clear step-by-step approach, is essential. Encompassed in this is the importance of accommodating changes in key personnel and of addressing the impact this may have on the workforce initiative. Therefore, the focus of the initiative must consider organizational as well as key stakeholder priorities. There must also be an available avenue to escalate concerns to a key organizational decision maker - this reinforces the need for executive-level support for workforce reform initiatives and how important it is that 


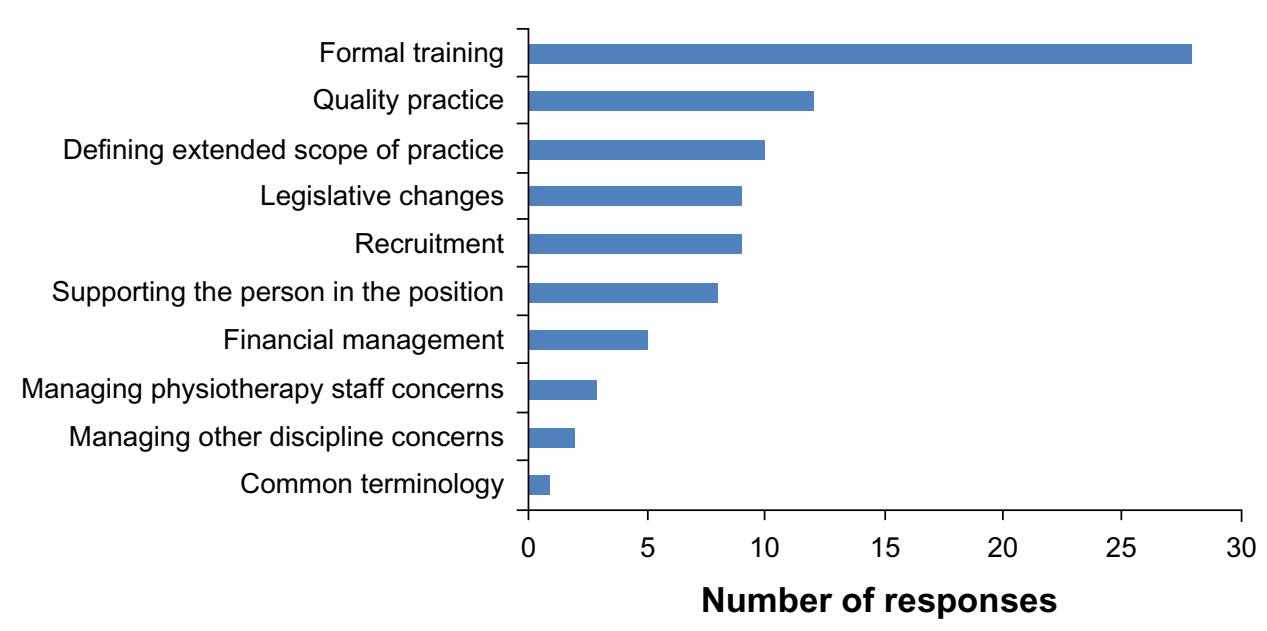

Figure I The importance of broad themes.

the new initiatives target key organizational objectives to engender support from the executive team.

This theme was strongly linked with demonstrable provision of quality services that are defensible within and outside the profession and the organization. "Quality" encompasses a range of constructs, including training, communication, service provision, and clinical and organizational outcomes. Interviewees particularly identified the importance of having clear evaluation strategies, encompassing both quantitative and qualitative aspects. Evaluation plans should be in place from inception of the initiative, to ensure that the new initiative can widely demonstrate the quality and accountability of the new service, to a range of stakeholder groups. In the health care facility in which this new workforce initiative was developed, an early evaluation of the engagement of the ESP physiotherapist in the orthopedic outpatient clinic was able to demonstrate significant impacts, reducing waiting list numbers and waiting times. ${ }^{17}$ The ESP initiative also provided previously unavailable, alternative options for care of people on the waiting list for consultation with the orthopedic surgeon. This evaluation found that for these people, access to care options, such as allied health treatment, exercise programs, early imaging, and/or timely injections, produced significant improvements in health and wellbeing, which meant that many patients did not need to consult an orthopedic surgeon. By offering alternative care as appropriate, people who remained on the waiting list were those that generally proceeded to surgery as their best treatment option. ${ }^{17}$

The issues contained within the broad theme of defining ESP highlighted the need for clearly articulating and communicating, within the physiotherapy discipline and to other disciplines, what tasks would/could be undertaken by the ESP physiotherapist. This needs to be planned well in advance and based on an understanding of the practitioner who traditionally practiced these tasks (and with what measures of effectiveness). In communicating the purpose of the ESP physiotherapy position to others, identifying and recognizing perceived threats (for instance threats to the status quo or to individual roles and positions, as well as skepticism regarding the future of the new workforce initiative) was essential. In addition, visionary support needed to be provided by representatives of the key stakeholder groups to the physiotherapist entering an ESP role, to ensure that he/she was comfortable relinquishing traditional within-scope tasks. Support was also required for individuals in other disciplines who may have been relinquishing their traditional tasks to an ESP physiotherapist and who might be taking on other (and new) roles as a result of workforce redesign. The importance of having a credible change champion to support the ESP physiotherapy service was raised, particularly one from the discipline whose tasks were being mirrored by the ESP practitioner (ie, medicine). This highlights the importance of planning, communicating, championing, and identifying and eliminating threat (perceived or real).

The themes of recruitment, supporting the person in the job, financial management, and managing physiotherapy staff concerns reflected concerns within the discipline (physiotherapy manager and ESP physiotherapist) and from the policy-maker. These were the areas perhaps least welladdressed in the research to date on ESP physiotherapy initiatives. The ESP physiotherapist has traditionally been a discipline leader, not only promoting the nature and effectiveness of the physiotherapy profession to related disciplines but also, providing academic and clinical leadership within the profession. Thus, the person recruited for an ESP role needs to have a sound track record in clinical practice and research, 
as well as leadership attributes that will attract others, within and outside the profession. This person needs to share the vision for ESP, to work collaboratively with other disciplines, and to evaluate the service being provided, in terms of both health outcomes and costs. These individuals also need to be committed to the aim of providing good quality, equitable, accessible, and efficient patient care within local workforce constraints and service requirements.

The continuity and sustainability of this new workforce initiative is the least well addressed area of concern, particularly if it is not underpinned by sustainable funding to maintain, grow, and develop this workforce. To date, despite efforts to ensure that well-trained staff are appropriately appointed to an increasing number of ESP physiotherapy positions, and the potential for these positions to relieve medical staff of more routine activities, ${ }^{14,16,17}$ there is only a small amount of ongoing funding for this in this health care facility. Thus, new positions are generally funded on short-term bases that are rarely sustainable, may not attract the right people to the position, and may not allow for appropriate research and evaluation strategies to be developed. Consequently, there are concerns relating to the capacity of the health care facility to cover annual leave and sick leave, as well as to undertake effective succession planning. It was specifically recognized by the physiotherapy manager and ESP physiotherapist that the appropriately qualified personnel for these positions may have competing career aspirations and opportunities, including research, participation in elite sport, and teaching. Therefore a succession plan is essential, and without the allocation of appropriate funding to have "in-training" positions, there is a significant risk that these positions could be vacant for long periods or only filled on a part-time basis. Additional funding implications include exploring the benefit of these roles in other clinical areas.

A second important component of sustainability includes sustainability of skills. The Physiotherapy Board of Australia provides guidance with relation to the continuing professional development requirements for physiotherapists working within traditional scope. ${ }^{27}$ Support for continuing education is not necessarily translated directly into sustainability of new ESP skills and tasks. Therefore, there should also be a recognized continuing professional development approach for physiotherapists working in ESP roles.

A third component of sustainability relates to the capacity of a suitably trained ESP physiotherapist to independently prescribe. At this point in time, the ESP physiotherapists in this health care facility do not have an ongoing prescription permit, and this poses perhaps the biggest challenge to the sustainability of the new service. Currently, physiotherapist prescription is not permitted under the state/ territory Medicines, Poisons and Therapeutic Goods Act. ${ }^{28}$ The process of authorization to prescribe to date, has been via an annual individual permit granted by the Government's Chief Health Officer. These permits require annual renewal, based on evidence of individual quality and safety that is acceptable to others. Each time a permit is sought, the Pharmaceutical Services Section at Health Protection Services is required to undertake a merit-basis assessment of the application. This is resource-intensive, and the need to annually renew permits is akin to keeping the ESP initiative in a "trial" phase indefinitely. At present, workload pressure on the Health Protection Services team are such that no further physiotherapy prescribing permits are being approved. The Health Protection Services team advised that if physiotherapist prescription in the ESP service is considered a priority, it requires a change to Commonwealth or state/ territory legislation (personal communication, September 2013). An example of this process is the recent change that allows endorsed optometrists to prescribe eye medications relating to any Schedule 2, 3, or 4 medicine, within the meaning of the current poisons standard under section 52D of the Therapeutic Goods Act 1989 (Commonwealth), that is used in the treatment of conditions of the eye. ${ }^{29}$ The list of approved medications is published on the Optometry Board's website. ${ }^{29}$

\section{Conclusion}

We undertook this research to ensure that introduction of new ESP allied health roles in Australian health care settings could learn from UK experiences and them, from ours. It was clear from the fragmentation of effort reported in the UK literature that Australian initiatives to introduce new ESP roles in any allied health discipline could benefit from a business plan that incorporated broad stakeholder perspectives. The ESP initiative reported in this paper was an Australian first. ${ }^{17,19}$ Had some of the stakeholder concerns reported in this paper been identified at the beginning of the project, a clearer path might have been charted, solutions might have been available when unexpected problems arose, and fewer barriers encountered. Some issues identified in this paper are further progressed than others in terms of resolution, and some are yet to be appropriately addressed. Consequently, to date, the workforce initiative of extending the scope of physiotherapy services is yet to be designated as a recognized new service in the health care facility. Indeed, the issue of obtaining and maintaining prescription rights for appropriately-trained ESP 
physiotherapists would appear, at present, to be an almost impenetrable barrier, without significant efforts to rewrite legislation.

We suggest, from our lessons, that Australian ESP allied health initiatives to improve clinical services should have a business case developed prior to its implementation. The business case should consider:

- The nature of the workforce reform initiative (a good idea being piloted, which may or may not proceed, vs a new, ongoing, evidence-based service)

- The credibility of the new service in the eyes of its own profession and other professions

- Whether there is precedence for the new service and what evidence is required to support it

- On whom the new workforce reform initiative will impact and what concerns might be raised about its viability and credibility

- The likely impact of the new service on the quality of patient care, described by the Institute of Medicine in terms of costs, effectiveness, equity, access, timeliness, patient-centeredness, and efficiency ${ }^{25}$

- Measures of outcomes to demonstrate the quality of the service

- Measures that reflect the appropriateness and acceptability of mirroring or sharing of tasks with other disciplines

- The training required to support the new service, including affordability, delivery modes, and content

- Legislative changes required to sustainably support the new ESP role and an identification of whose responsibility it is to steer these changes

- The availability of appropriately-trained individuals in the ESP role who satisfy the criteria for discipline leadership and who are credible champions for professional change

- Funding to sustainably support the new service

- Agreement on how much remuneration for the ESP position should flow back to the "home" department/ area, given that the service will be provided within, and savings made for, other departments of the health care institution

- The availability of change champions outside the discipline to support the initiative.

While not all these issues may be relevant to all ESP allied health clinical care initiatives in all Australian health care facilities, early consideration of these matters in the planning phase will assist with the development of successful, sustainable, transferable, measurable, and innovative initiatives. The potential is huge for new workforce models such as ESP allied health roles to improve the efficiency, effectiveness, quality, and costs of health care in Australia. Opportunities for sustainable change should not be squandered by poor planning.

\section{Disclosure}

The authors report no conflicts of interest in this work.

\section{References}

1. McPherson K, Kersten P, George S, et al. A systematic review of evidence about extended roles for allied health professionals. $J$ Health Serv Res Policy. 2006;11(4):240-247.

2. Australian Physiotherapy Association (APA). Scope of Practice [position statement]. Melbourne: Australian Physiotherapy Association; 2009. Available from: http://www.physiotherapy.asn.au/DocumentsFolder/ Advocacy_Position_Scope_of_Practice_2009.pdf, 2009. Accessed February 2, 2014.

3. Reeve S, May S. Exploration of patients' perspectives of quality within an extended scope physiotherapists' spinal screening service. Physiother Theory Pract. 2009;25(8):533-543.

4. MacKay C, David AM, Mahomed N, Badley EM. Expanding roles in orthopaedic care: a comparison of physiotherapist and orthopaedic surgeon recommendations for triage. J Eval Clin Pract. 2009;15(1): $178-183$.

5. European Parliament, Council. Working Time Directive. Brussels: European Parliament; 1998. Available from: http://ec.europa.eu/social/main.js p?catId=706\&langId=en\&intPageId=205. Accessed February 2, 2014.

6. Kersten P, McPherson K, Lattimer V, George S, Breton A, Ellis B Physiotherapy extended scope of practice - who is doing what and why? Physiotherapy. 2007;93(4):235-242.

7. Harrison J, Rangan A, Shetty A, Robinson C. Reducing waiting times: physiotherapy shoulder assessment clinic. Int JTher Rehabil. 2001;8(2): 57-59.

8. Maddison P, Jones J, Breslin A, et al. Improved access and targeting of musculoskeletal services in northwest Wales: targeted early access to musculoskeletal services (TEAMS) programme. BMJ. 2004;329(7478): $1325-1327$.

9. Moloney A, Dolan M, Shinnick L, Murphy M, Wallace L. A 6-month evaluation of a clinical specialist physiotherapist's role in a fracture clinic. Physiother Pract Res. 2009;30(1):8-15.

10. Hattam P. The effectiveness of orthopaedic triage by extended scope physiotherapists. Clinical Governance: An International Journal. 2004;9(4):244-252.

11. Hattam P, Smeatham A. Evaluation of an orthopaedic screening service in primary care. Clin Perform Qual Health Care. 1999;7(3):121-124.

12. Atkins E. Physiotherapists' experience of implementing their injection therapy skills. Physiotherapy. 2003;89(3):145-157.

13. Dawson LJ, Ghazi F. The experience of physiotherapy extended scope practitioners in orthopaedic outpatient clinics. Physiotherapy. 2004;90(4):210-216.

14. Oldmeadow LB, Bedi HS, Burch HT, Smith JS, Leahy ES, Goldwasser M. Experienced physiotherapists as gatekeepers to hospital orthopaedic outpatient care. Med J Aust. 2007;186(12):625-628.

15. Blackburn MS, Cowan SM, Cary B, Nall C. Physiotherapy-led triage clinic for low back pain. Aust Health Rev. 2009;33(4):663-670.

16. Anaf S, Sheppard LA. Lost in translation? How patients perceive the extended scope of physiotherapy in the emergency department. Physiotherapy. 2010;96(2):160-168.

17. Morris J, Grimmer-Somers K, Kumar S, et al. Effectiveness of a physiotherapy-initiated telephone triage of orthopedic waitlist patients. Patient Relat Outcome Meas. 2011;2:151-159.

18. Birch S, Mason T, Sutton M, Whittaker W. Not enough doctors or not enough needs? Refocusing health workforce planning from providers and services to populations and needs. J Health Serv Res Policy. Epub April 24, 2013. 
19. Gilmore LG, Morris JH, Murphy K, Grimmer-Somers K, Kumar S. Skills escalator in allied health: a time for reflection and refocus. J Healthc Leadersh. 2011;3:53-58.

20. Pencheon D. Developing a sustainable health and care system: lessons for research and policy. J Health Serv Res Policy. 2013;18(4):193-194.

21. Borland J. Report to the Australian Competition and Consumer Commission on: Australian Medical Workforce Advisory Committee-The Orthopaedic Surgery Workforce in Australia, an Update: 1998 to 2009. Canberra: Australian Competition and Consumer Commission; 2011. Available from: http://www.accc.gov.au/system/files/Report to ACCC - AMWAC Orthopaedic Surgery Workforce in Australia.pdf. Accessed February 2, 2014.

22. Robert G. Rethinking policy approaches to measuring and improving patient experience. J Health Serv Res Policy. 2013;18(2):67-69.

23. Rice PL, Ezzy D. Qualitative Research Methods: A Health Focus. Oxford: Oxford University Press; 1999.

24. Fossey E, Harvey C, McDermott F, Davidson L. Understanding and evaluating qualitative research. Aust N Z J Psychiatry. 2002;36(6): 717-732.

25. Kohn LT, Corrigan JM, Donaldson MS, editors. To Err is Human: Building a Safer Health System. Washington, DC: Institute of Medicine (IOM); 2000. Available from: http://books.nap.edu/openbook. php?isbn=0309068371. Accessed February 2, 2014.
26. Physiotherapy Board of Australia. About the National Boards and AHPRA. Available from http://www.physiotherapyboard.gov.au/CodesGuidelines/Code-of-conduct.aspx. Accessed February 2, 2014.

27. Physiotherapy Board of Australia. Guidelines for Continuing Professional Development. Melbourne: Physiotherapy Board of Australia; 2010. Available from: http://www.physiotherapyboard.gov. $\mathrm{au} /$ documents/default.aspx?record=WD10\%2F1308\&dbid=AP\&ch ksum $=$ QScN2VUhX8\%2Fvv\%2BXYmZyPEQ\%3D\%3D. Accessed February 2, 2014.

28. Australian Capital Territory. Medicines, Poisons and Therapeutic Goods Act 2008. [Republication No 10; Effective: February 25, 2013]. Canberra: Australia Capital Territory Counsel; 2013.

29. Optometry Board of Australia. Endorsement for Scheduled Medicines Registration Standard. Melbourne: Optometry Board of Australia; 2010. Available from: http://www.optometryboard.gov.au/documents/ default.aspx?record=WD10\%2F158\&dbid=AP \&chksum=uA2c3Oie3 cwpQqUMXLHfKg\%3D\%3D. Accessed October 7, 2013.
Journal of Multidisciplinary Healthcare

\section{Publish your work in this journal}

The Journal of Multidisciplinary Healthcare is an international, peerreviewed open-access journal that aims to represent and publish research in healthcare areas delivered by practitioners of different disciplines. This includes studies and reviews conducted by multidisciplinary teams as well as research which evaluates the results or conduct of such teams or

\section{Dovepress}

healthcare processes in general. The journal covers a wide range of areas and welcomes submission from practitioners at all levels, from all over the world. The manuscript management system is completely online and includes a very quick and fair peer-review system. Visit http://www.dovepress.com/testimonials.php to read real quotes from published authors. 